\section{NUMBER CRUNCH}

$33 \%$ is the proportion of

Americans following science and technology news "very closely" during 1986-89, according to the snappily titled Pew News Interest Index.

$16 \%$ is the corresponding figure for 2000-06.

$17 \%$ is the number of news junkies with a keen interest in celebrity scandals, showing that the world of science is now measurably less popular than Paris Hilton, though perhaps not as much as Sidelines might have thought.

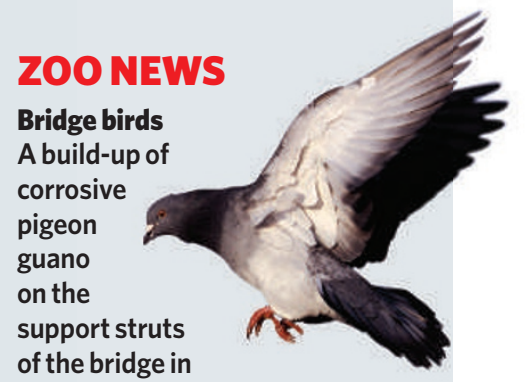

Minneapolis that collapsed on 1 August might have played a role in the disaster. Some experts think that ammonia in the droppings could have weakened the steel beams.

\section{WORDWATCH}

Slime-Snake-Monkey-People Evangelist Robert Bowie Johnson has coined this term for darwinists. He suggests that Christians should use it to 'shame' those who accept evolution over Genesis. Talk us through the snake-to-monkey step, would you, Bob?

\section{SCORECARD}

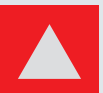

Chewing gum

Archaeologists at Harvard University have obtained 2,000-year-old DNA from wads of plant matter that Native Americans apparently used as chewing gum.

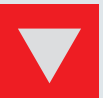

Chewing gum Meanwhile, the oldest-ever 'chewing gum' has been found in Finland. The 5,000-year-old morsel, complete with toothmarks, was a distinctly unappetizing lump of birch bark tar.

Sources: Pew Research Center, Associated Press, Christian News Wire, Science, The Guardian

\title{
Cheaper approaches to flu divide researchers
}

As governments race to stockpile Tamiflu and other antivirals in preparation for the next influenza pandemic, scientists are starting to look at a different approach - drugs that modulate the immune system.

Proponents argue that these abundant and cheaper drugs, such as statins, might be a useful option where antivirals are unavailable or have been given too late. But sceptics fear that they might do more harm than good because they suppress the body's immune response to the virus. With the latest studies seeming to contradict each other, the flu community is divided about the best way to proceed.

The high mortality associated with viruses such as avian flu is thought to be because the immune system has a massive over-reaction to the infection. The body hikes its production of immune molecules called cytokines, which flood into the bloodstream, causing what's known as a cytokine storm. This triggers inflammation and lung damage, and can lead to multiple organ failure and death. So rather than the usual approach of targeting the virus, researchers hope that mortality could be reduced by using drugs that regulate this immune response.

At present, planning for pandemics is focused on stockpiling antivirals. But becasue these drugs, such as Tamiflu, are expensive and difficult to manufacture, there may not be enough to go round by the time another pandemic strikes, and

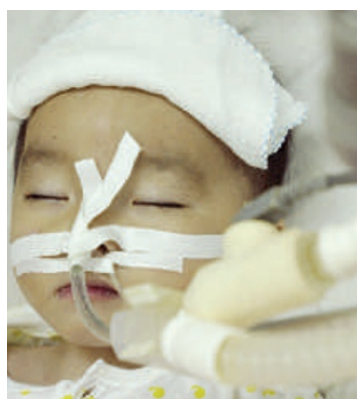

"We must urgently evaluate agents that are already available and affordable to people in all countries." poorer countries may not have access to them at all.

"If we are to be serious about confronting a pandemic, we must urgently evaluate agents that are already available and affordable to people in all countries," says David Fedson, former director of medical affairs at Parisbased Aventis Pasteur, now Sanofi-Aventis.

This month, Ian Clark's group at the Australian National University in Canberra published a study ${ }^{1}$ investigating the effectiveness of another immune-modulating drug, called gemfibrozil, in mice infected with the influenza virus. Gemfibrozil is a fibrate, a class of drug widely prescribed to lower lipid concentrations in the blood. But it also inhibits the release of inflammatory cytokines such as tumour-necrosis factor, interferon- $\gamma$ and interleukin- 6 , and stimulates production of the anti-inflammatory cytokine interleukin-4. Clark's team infected mice with $\mathrm{H} 2 \mathrm{~N} 2$ - the flu strain that caused the 1957 pandemic. Four days later, once the rodents had become sick, they injected 46 mice with 60 milligrams per kilogram of body weight of gemfibrozil once a day for six days. Twice as many of the treated mice (52\%) survived compared with controls (26\%).

\section{Tread with caution}

"The paper should spark some interest, but even more caution," says Erik De Clercq, a virologist at the Catholic University of Leuven in Belgium. He points out that it is difficult to extrapolate from Clark's H2N2 mouse model to the $\mathrm{H} 5 \mathrm{~N} 1$ strain in humans. For example, he says, it did not show that increased survival was directly due to inhibition of the cytokine storm. Clark agrees and is planning further studies to rule out the possibility of confounding effects, such as the drug having a direct antiviral effect.

However, two other studies suggest that the cytokine storm might not be as fatal as thought. In one study ${ }^{2}$, mice that had one cytokine pathway knocked out showed no reduction in mortality compared with normal mice after they were infected with $\mathrm{H} 5 \mathrm{~N} 1$. "These results refute the popular paradigm that the cytokine storm is the cause of death during H5N1 infection," says Robert Webster, who carried out the study with his colleagues at St Jude Children's Research Hospital in Memphis, Tennessee.

In the second study ${ }^{3}$, by Jacqueline Katz's group at the Centers for Disease Control and Prevention in Atlanta, Georgia, mice deficient in the inflammatory cytokine interleukin-1 receptor had worse mortality, higher viral loads and more inflammation than did controls when infected with the HK/486 virus.

But both studies tested only three to five mice in each experiment, and looked at only a few of the many overlapping cytokine path- 


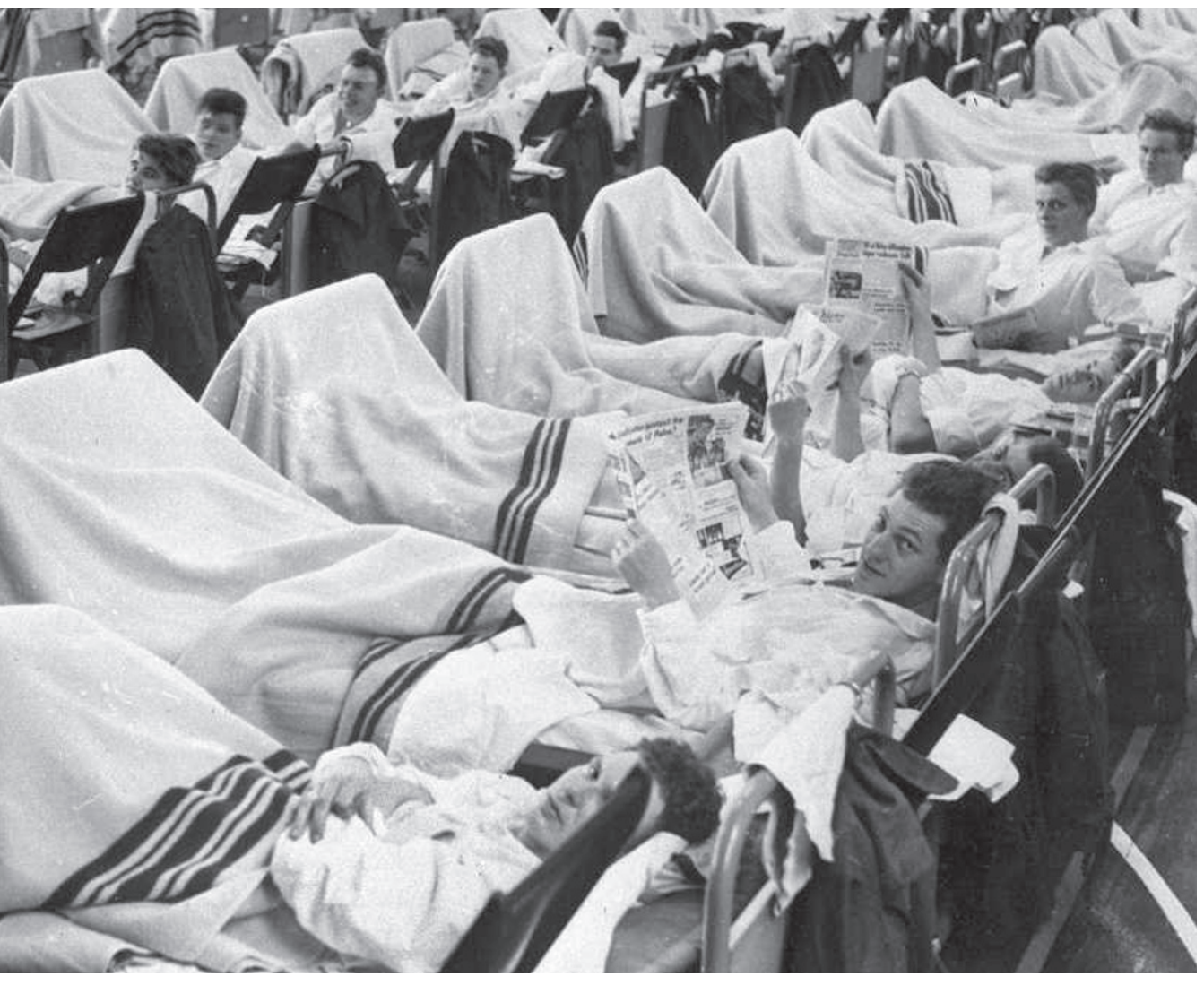

Viral overload: the 1957 flu pandemic affected millions of people around the world.

ways, points out Eric Mortensen of the Audie L. Murphy Veterans hospital in San Antonio, Texas. They need to be replicated with a much larger number of mice, and examining other potential pathways, says Mortensen.

Clark even asserts that "if the same outcomes had been repeated at $n=15$, the statistics would show the opposite of what Webster's group claimed," he says. However, Rachelle Salomon, the lead author of the study, says "large numbers of mice would be ideal, but due to our experience with these viruses, I am confident with the result and conclusions". The groups were small because the experiments needed to be done in laboratories with an approved biosafety level of at least 3 (the maximum is 4), she explains. Because Australia has different standards, Clark was able to use level 2 facilities.

Statins - another lipid-lowering class of drug with anti-inflammatory effects - might be a better bet than gemfibrozil, says Mortensen, who has papers in the press showing that these drugs lower the number of deaths from pneumonia. And then there is a preliminary analysis ${ }^{4}$ of 20,000 patients older than 50 years enrolled in the University Medical Center Utrecht primary-care network in the Netherlands by Eelko Hak and his colleagues at the university. They found that during flu epidemics, people who took statins were $28 \%$ less likely to develop res- piratory disease and 51\% less likely to die from any cause than were those who did not take the drugs. Another, case-control study ${ }^{5}$ of 130,000 patients also found that current use of statins lowered mortality from pneumonia.

But Frederick Hayden of the World Health Organization's global influenza programme says that pandemic flu involves protracted viral replication, often over weeks, so using immune drugs when viral replication is high could do more damage than good. A more sensible idea might be to study joint treatments with immune modulators and antivirals, he says.

But definitive answers can only come from clinical trials done immediately after the onset of a pandemic, says Peter Openshaw of Imperial College London. "We need to be able to plan ahead and set up trial protocols, but that's not easy to do when we don't know when an epidemic may strike."

Declan Butler

1. Budd, A. et al. Antimicrob. Agents Chemother. 51, 2965-2968 (2007).

2. Salomon, R., Hoffmann, E. \& Webster, R. G. Proc. Natl Acad. Sci. USA 104, 12479-12481 (2007).

3. Szretter, K. J. et al. J. Virol. 81, 2736-2744 (2007).

4. Hak, E., Verheij, T., van Essen, G., Bonten, M. J. M. \& Hoes, A. 16th European Congress of Clinical Microbiology and Infectious Diseases, Nice, abstr.; www.blackwellpublishing. com/eccmid16/abstract.asp?id=49073 (2006).

5. Schlienger, R. G., Fedson, D. S., Jick, S. S., Jick, H. \& Meier, C. R. Pharmacotherapy 27, 325-332 (2007).

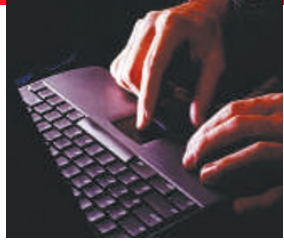

THE GREAT BEYOND

Check out our new blog, rounding up science stories from around the world. http://blogs. nature.com/news/ thegreatbeyond/

\section{Flying insects threaten to deafen Japan}

A cicada known as the kumazemi is descending on Japan en masse, deafening the citizens and wreaking havoc on the country's fibre-optic system. The 6- to 7-centimetre-long black cicada (Cryptotympana facialis) inhabits western Japan and subtropical regions of eastern Asia. This August is expected to be the largest and noisiest cicada summer in the insect's four-year cycle.

Surveys of the shells shed by maturing cicadas at a park in Osaka, carried out by Shigehiko Shiyake, curator of the Osaka Museum of Natural History, and Eiji Numata, a biologist at Osaka University, show that the cicada population increases every year for four years, after which it returns to base level and the cycle restarts. From the past three years' data, the scientists calculate that this year will be the four-year peak, with nearly 2.5 times as many cicadas as in 2006. The noise level is also set to climb. Measured at 90.4 decibels at another Osaka park last year, this year the same spot is expected to hit 94 decibels - decibels follow a logarithmic scale, so that's more than double the volume. Prolonged exposure to this level of noise can cause deafness.

The kumazemi are also cutting households off from their Internet. Apparently mistaking fibre-optic cables for withered branches, they have been punching their one-millimetre-diameter ovipositors into the cables and laying eggs. In at least 1,000 cases over the past two years, the cicadas have either severed the cable or opened up a hole, allowing water to seep in. The Osaka-based Nippon Telephone and Telegraph West Corporation has responded by creating new cables that lack the grooves that the cicadas target with their ovipositors and by adding another protective plastic layer to the cable. David Cyranoski

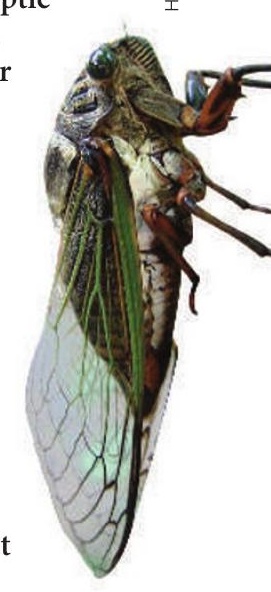

$\square$ 